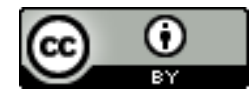

Esta obra está sob o direito de Licença Creative Commons Atribuição 4.0 Internacional.

\title{
FAMÍLIA E LEITURA E ENSINO FUNDAMENTAL E DISLEXIA E METACOGNIÇÃO
}

Elizabeth Calheiros Borges ${ }^{1}$

\begin{abstract}
RESUMO
O habito da leitura é de grande importância para o desenvolvimento da criança e com a prática a criança cresce, mentalmente, em vários aspectos, já que esta prática estimula a imaginação, desenvolve a capacidade criativa, desenvolve a habilidade linguística, trabalha as emoções, além de melhorar suas habilidades de comunicação. Esta pesquisa buscou analisar a produção científica sobre a relação entre a Leitura, a família, o ensino fundamental, a Dislexia e a Metacognição, analisando produções científicas publicadas entre 2015 e 2019, nos sites periódicos da SciELO, CAPES, MEDLINE, LILACS. Trata-se de uma revisão sistemática de literatura integrativa. Utilizando os descritores estruturados no DeCS e MeSH. O período de coleta de dados ocorreu entre agosto e setembro de 2019. Adotou-se como critério de inclusão de artigos científicos e, como critérios de exclusão artigos que não contemplam a temática estudada. Espera-se poder compreender que a família tem um papel fundamental e de suma importância no processo de aprendizagem da criança, e que esta instituição é extremamente importante para o aluno portador de dislexia e até mesmo do não portador, e que estes terão um desempenho metacognitivo com maior aproveitamento quando a escola e a família trabalham juntos.
\end{abstract}

PALAVRAS-CHAVE: Família. Leitura. Dislexia. Metacognição.

\footnotetext{
${ }^{1}$ bethcalheiros@bol.com.br
} 


\section{INTRODUÇÃO}

É essencial que a família se integre na vida escolar dos seus educandos, de maneira a dar o apoio que estas necessitam para o seu desenvolvimento. Neste sentido, é também necessário que as escolas promovam estratégias que impulsionem um maior envolvimento das famílias no processo de aprendizagem das crianças. No que diz respeito à família, segundo Relvas (1996), esta "é uma rede complexa de relações e emoções na qual se passam sentimentos e comportamentos com as alterações decorridas ao longo dos tempos no seio familiar." Assim, podemos considerar a família como o primeiro e principal educador da criança, onde ela se integra e vai desenvolver primeiramente a sua personalidade (PRATA, 2018).

Os autores citados demonstram a importância da relação entre a família, a escola, o desenvolvimento cognitivo da criança, seja ela ou não portadora de alguma deficiência de aprendizagem. Sendo a família o primeiro e o principal educador de uma criança seus hábitos ajudam no desenvolvimento e na aprendizagem escolar. Uma família que possui o hábito da leitura permitirá que a criança possa ter um melhor desenvolvimento em sua vida escolar.

\section{METODOLOGIA}

A presente pesquisa adotou como método a revisão sistemática, conforme as etapas expostas no Quadro 1, atendendo aos critérios como a definição do tema, pergunta norteadora, objetivo e estratégias de busca, além de dados lógicos da pesquisa, sites e bibliotecas acessados, descritores, string de busca, período de coleta dos dados e critérios de exclusão e inclusão dos artigos utilizados. 
QUADRO 1

DETALHAMENTO DAS ETAPAS DA REVISÃO SISTEMÁTICA INTEGRATIVA.

\begin{tabular}{|c|c|c|c|c|}
\hline ETAPA & TÓPICOS DE CADA ETAPA & \multicolumn{3}{|c|}{ DETALHAMENTO DE CADA TÓPICO } \\
\hline $1^{\mathrm{a}}$ & Tema & \multicolumn{3}{|c|}{ Família E Leitura E Ensino Fundamental E Dislexia E Metacognição } \\
\hline & Pergunta norteadora & \multicolumn{3}{|c|}{ O desejo da leitura surge no ambiente familiar? } \\
\hline & Objetivo geral & \multicolumn{3}{|c|}{ Integrar a produção científica sobre o hábito da leitura no ambiente familiar } \\
\hline & Estratégias de busca & \multicolumn{3}{|c|}{$\begin{array}{l}\text { 1. Cruzamento de descritores por meio do operador boleano AND; } \\
\text { 2. Uso de aspas nos politermos (descritor com mais de um termo) para que } \\
\text { a varredura de artigos científicos contemplasse o termo exato; } \\
\text { 3. Uso de descritores estruturados (codificação) no DeCS ou MeSH; } \\
\text { 4. Uso de metadados (filtros) }\end{array}$} \\
\hline & \multirow[t]{3}{*}{ Banco de terminologias } & \begin{tabular}{l|l} 
Banco & \\
\end{tabular} & \multicolumn{2}{|c|}{ Link } \\
\hline & & DeCs & \multicolumn{2}{|c|}{ https://decs.bvsalud.org/ } \\
\hline & & $\mathrm{MeSH}$ & \multicolumn{2}{|c|}{ https://www.ncbi.nlm.nih.gov/mesh/ } \\
\hline & \multirow[t]{4}{*}{ Descritores livres e estruturados } & Descritor & $\begin{array}{l}\text { DeCS(Registr } \\
\text { o) }\end{array}$ & MeSH(identificador Único) \\
\hline & & 1. Familia & 23905 & D005190 \\
\hline & & 2. Adolescentes & 29315 & D000293 \\
\hline & & 3. Leitura & 12366 & D011932 \\
\hline & Bibliotecas Virtuais & \multicolumn{3}{|c|}{$\begin{array}{l}\text { 1. Biblioteca Virtual da saúde (BVS) - incluindo as fontes de informações, } \\
\text { que compõe sua rede: Literatura Latino-Americana e do Caribe em } \\
\text { Ciências da Saúde (LILACS), Scientific Electronic Library Online } \\
\text { (SciELO); } \\
\text { 2. ScienceDirect; } \\
\text { 3. PubMed; } \\
\text { 4. SciELO; } \\
\text { 5. LILACS. }\end{array}$} \\
\hline & String de busca & \multicolumn{3}{|c|}{$\begin{array}{l}\text { Family AND Reading AND (Ensino Fundamental) AND Dyslexia AND } \\
\text { Metacognition }\end{array}$} \\
\hline
\end{tabular}




\begin{tabular}{|c|c|c|c|c|c|c|}
\hline & \multirow[t]{6}{*}{ Bibliotecas vistuais } & & & \multicolumn{3}{|c|}{ Link } \\
\hline & & \multicolumn{2}{|l|}{ Scielo } & \multicolumn{3}{|c|}{ https://scielo.org/pt/ } \\
\hline & & \multicolumn{2}{|l|}{ BVS } & \multicolumn{3}{|c|}{ https://bvsalud.org/ } \\
\hline & & \multicolumn{2}{|c|}{$\begin{array}{l}\text { Periódicos da } \\
\text { CAPES }\end{array}$} & \multicolumn{3}{|c|}{$\begin{array}{l}\text { https://www-periodicos-capes-gov- } \\
\text { br.ezl.periodicos.capes.gov.br/ }\end{array}$} \\
\hline & & \multicolumn{2}{|c|}{ WILEY } & \multicolumn{3}{|c|}{ https://www.onlinelibrary.wiley.com/ } \\
\hline & & \multicolumn{2}{|c|}{ Sciencedirect } & \multicolumn{3}{|c|}{ https://www.sciencedirect.com/ } \\
\hline \multirow[t]{3}{*}{$2^{\mathbf{a}}$} & Período de coleta de dados & \multicolumn{5}{|c|}{24 de agosto de 2019 à 28 de setembro de 2019} \\
\hline & Critério de inclusão & \multicolumn{5}{|c|}{$\begin{array}{c}\text { 1. Texto (artigo de opinião de espécie científico). } \\
2 . \quad \text { Publicação (2015-2019). }\end{array}$} \\
\hline & Critérios de exclusão & \multicolumn{5}{|c|}{$\begin{array}{l}\text { 1. Texto completo (disponível/free) do tipo: artigo original, artigo de } \\
\text { revisão, artigo na imprensa, recurso, editorial, perspectiva e pesquisa } \\
\text { transacional; } \\
\text { Artigos que não contemplavam a relação entre o uso materno, no } \\
\text { pré-natal, e/ou infantil de antibióticos com o desenvolvimento da } \\
\text { obesidade infantil. }\end{array}$} \\
\hline $3^{\mathbf{a}}$ & \multicolumn{5}{|c|}{$\begin{array}{l}\text { Número de trabalhos selecionados para revisão sistemática integrativa a partir da leitura dos } \\
\text { agentes indexadores das publicações (resumo, palavras-chave e título) e resultados, os quais } \\
\text { deveriam conter os descritores utilizados nesse estudo. }\end{array}$} & 6 \\
\hline $4^{\mathrm{a}}$ & \multicolumn{5}{|c|}{ Categorias obtidas com a análise dos documentos investigados online gratuitos e de livre acesso. } & 3 \\
\hline \multirow[t]{2}{*}{$\mathbf{5}^{\mathbf{a}}$} & \multirow[t]{2}{*}{ Tecnologias digitais utilizadas } & $\begin{array}{l}\text { Tecnologia } \\
\text { (software ou } \\
\text { website) }\end{array}$ & & Link & \multicolumn{2}{|c|}{ Utilidade } \\
\hline & & $\begin{array}{c}\text { WordArt: nuvem } \\
\text { de palavras }\end{array}$ & & wordart.com/ & \multicolumn{2}{|c|}{$\begin{array}{l}\text { Construir nuvem de palavras e } \\
\text { frequência das palavras-chave } \\
\text { para criar as categorias } \\
\text { temáticas. }\end{array}$} \\
\hline
\end{tabular}

Fonte: elaborada pelos autores. 


\section{RESULTADOS}

Tabela 1 - Corresponde a quantidade das varreduras realizadas com cinco bases de buscas. Foram detectadas 2.399 publicações científicas nos bancos de dados, das quais 225 eram artigos científicos disponíveis após o uso dos filtros desses, foram feitos 14 downloads. Entretanto, obedeceram aos critérios inclusão 7 artigos científicos, sendo submetidos às etapas da revisão integrativa.

TABELA 1

STRING DE BUSCAS E BIBLIOTECAS VIRTUAIS CONSULTADAS

\begin{tabular}{|c|c|c|c|c|c|}
\hline $\begin{array}{l}\text { Descritores/ } \\
\text { String de } \\
\text { busca }\end{array}$ & $\begin{array}{c}\text { Bases de } \\
\text { dados }\end{array}$ & $\begin{array}{c}\text { Total de } \\
\text { publicações } \\
\text { sem o filtro } \\
\text { "assuntos } \\
\text { principal" }\end{array}$ & $\begin{array}{c}\text { Textos } \\
\text { completos } \\
\text { após } \\
\text { aplicar } \\
\text { filtros }\end{array}$ & $\begin{array}{c}\text { Downloads } \\
\text { de textos } \\
\text { completos }\end{array}$ & $\begin{array}{c}\text { Textos } \\
\text { aproveitados } \\
\text { na Revisão } \\
\text { Sistemática } \\
\text { Integrativa }\end{array}$ \\
\hline \multirow{5}{*}{$\begin{array}{c}1^{o} \text { String } \\
\text { Família AND } \\
\text { leitura AND } \\
\text { Ensino } \\
\text { fudamental }\end{array}$} & Scielo & 10 & 1 & 0 & 0 \\
\hline & $\begin{array}{l}\text { Periódicos da } \\
\text { CAPES }\end{array}$ & 2.240 & 138 & 0 & 0 \\
\hline & $B V S$ & 56 & 16 & 5 & 3 \\
\hline & WILEY & 22 & 20 & 0 & 0 \\
\hline & ScienceDirect & 34 & 23 & 0 & 0 \\
\hline \multirow{5}{*}{$\begin{array}{c}2^{\circ} \text { String } \\
\text { Ensino } \\
\text { Fundamental } \\
\text { AND dislexia } \\
\text { AND } \\
\text { Metacognição }\end{array}$} & Scielo & 20 & 15 & 5 & 1 \\
\hline & $\begin{array}{l}\text { Periódicos da } \\
\text { CAPES }\end{array}$ & 5 & 1 & 0 & 0 \\
\hline & $B V S$ & 12 & 11 & 4 & 2 \\
\hline & WILEY & 0 & 0 & 0 & 0 \\
\hline & ScienceDirect & 0 & 0 & 0 & 0 \\
\hline Total & & 2.399 & 225 & 14 & 6 \\
\hline
\end{tabular}

Fonte: Elaboarada pelos autores

Dos 3 artigos (quadro 1) analisados, os 3 eram estudos primários (sendo os 3 estudos de caso). Quanto ao ano publicado, foram selecionados apenas os publicados entre o ano de 2016 e 2018. Os artigos estavam escritos em português.
Já no Quadro 2, foram analisados 3 artigos, 3 eram estudos primários (sendo os 3 estudos de caso). Quanto ao ano publicado, foram selecionados apenas os publicados entre o ano de 2016 e 2018 . Os artigos estavam escritos em português. 


\section{QUADRO 01 \\ DESCRIÇÃO DOS DOCUMENTOS (ARTIGOS) DE ACORDO COM OS CRITÉRIOS DE INCLUSÃO. $1^{\circ}$ STRING - FAMÍLIA AND LEITURA AND ENSINO FUNDAMENTAL}

\begin{tabular}{|c|c|c|c|c|c|}
\hline BASE & $\operatorname{AUTOR}(\mathbf{A})$ & TEMA & $\begin{array}{c}\text { DATA DE } \\
\text { PUBLICAÇÃO }\end{array}$ & $\begin{array}{c}\text { OBJETIVO DO } \\
\text { ESTUDO }\end{array}$ & CONCLUSÃO DO ESTUDO \\
\hline BVS & $\begin{array}{c}\text { Renata } \\
\text { Ribeiro; } \\
\text { Sylvia Maria } \\
\text { Ciasca; Iuri } \\
\text { Victor } \\
\text { Capelatto }\end{array}$ & $\begin{array}{c}\text { Relação entre } \\
\text { recursos familiares } \\
\text { e desempenho } \\
\text { escolar de alunos } \\
\text { do } 5^{\circ} \text { ano do } \\
\text { Ensino } \\
\text { Fundamental de } \\
\text { escola pública }\end{array}$ & 2016 & $\begin{array}{c}\text { Avaliar os recursos } \\
\text { do ambiente familiar } \\
\text { e correlacioná-lo ao } \\
\text { desempenho escolar } \\
\text { de alunos do } 5^{\circ} \text { ano } \\
\text { do Ensino } \\
\text { Fundamental de } \\
\text { escola pública } \\
\text { brasileira. }\end{array}$ & $\begin{array}{l}\text { A parceria escola e família é essencial à } \\
\text { aprendizagem, promovendo o sucesso escolar. Os } \\
\text { pais auxiliam a escola de acordo com a maneira com } \\
\text { que eles foram educados, porém famílias com baixo } \\
\text { grau de escolaridade se sentem perdidas diante das } \\
\text { tarefas. Os pais relatam, ainda, que sentem a } \\
\text { necessidade de maior orientação por parte da escola } \\
\text { de como devem auxiliarem seus filhos, segundo } \\
\text { pesquisa de Chechia \& Andrade. Concluindo, nessa } \\
\text { amostra houve correlação positiva entre desempenho } \\
\text { escolar e alguns itens do perfil do ambiente familiar: } \\
\text { passeios, atividades programadas extraescolares, } \\
\text { posse de livros, revistas e brinquedos e } \\
\text { acompanhamento de deveres escolares. Esses dados } \\
\text { indicam que, quando há estímulo e motivação no } \\
\text { ambiente familiar, há também melhores chances de as } \\
\text { crianças terem desempenho escolar satisfatório. } \\
\text { Sugere-se para pesquisas futuras que essa correlação } \\
\text { seja analisada também entre as esferas pública e } \\
\text { particular, a fim de que se possa obter dados } \\
\text { relevantes e significativos quanto à relação educação } \\
\text { e ambiente familiar na realidade brasileira. }\end{array}$ \\
\hline
\end{tabular}




\begin{tabular}{|c|c|c|c|c|c|}
\hline BVS & $\begin{array}{c}\text { Karina da } \\
\text { Costa; José } \\
\text { Maria } \\
\text { Montiel; } \\
\text { Daniel } \\
\text { Bartholomeu; } \\
\text { Camélia } \\
\text { Santina } \\
\text { Murgo; } \\
\text { Nathalia } \\
\text { Rodrigues } \\
\text { Campos }\end{array}$ & $\begin{array}{c}\text { Percepção do } \\
\text { suporte familiar e } \\
\text { desempenho em } \\
\text { leitura e escrita de } \\
\text { crianças do Ensino } \\
\text { Fundamental }\end{array}$ & 2016 & $\begin{array}{l}\text { Este estudo tem } \\
\text { como objetivo } \\
\text { avaliar as relações } \\
\text { entre suporte familiar } \\
\text { e desempenho de } \\
\text { leitura e escrita de } \\
\text { crianças de } 8 \text { a } 10 \\
\text { anos. }\end{array}$ & $\begin{array}{l}\text { Dentre as limitações deste estudo, cabe destacar que a } \\
\text { amostra é proveniente do Estado do Maranhão e a } \\
\text { maior parte dos estudos nacionais citados foi } \\
\text { realizada em São Paulo e Minas Gerais. Assim, é } \\
\text { interessante destacar que pode haver vieses culturais } \\
\text { que afetem as relações entre essas variáveis por um } \\
\text { lado e novas pesquisas com amostras de outros locais } \\
\text { devem ser feitas para examinar se as relações entre } \\
\text { essas variáveis se mantêm em outros contextos. Por } \\
\text { outro lado, aparentemente, os resultados dessa } \\
\text { pesquisa mantiveram consonância com a literatura } \\
\text { pertinente, apesar das diferenças culturais, } \\
\text { enfatizando o papel importante do suporte familiar no } \\
\text { desempenho de leitura e escrita. Novas investigações } \\
\text { poderiam se ater a uma metanálise dos estudos sobre } \\
\text { família e desempenho de leitura e escrita, visando à } \\
\text { caracterização de contribuições específicas de cada } \\
\text { aspecto relacionado a ela sobre este desempenho. } \\
\text { Chama a atenção também o fato de o fator de vínculo } \\
\text { afetivo não se relacionar ao desempenho em } \\
\text { português, o que seria esperado levando em } \\
\text { consideração os achados da literatura. Tal aspecto } \\
\text { convida a novas investigações, sobretudo dos efeitos } \\
\text { culturais e valorização cultural de certos tipos de } \\
\text { suporte familiar ou outros, já que certos aspectos } \\
\text { podem ser mais ou menos valorizados na escola em } \\
\text { decorrência da cultura local. }\end{array}$ \\
\hline
\end{tabular}




\begin{tabular}{|c|c|c|c|c|c|}
\hline BVS & $\begin{array}{c}\text { Claudia Sofia } \\
\text { Oliveira } \\
\text { Prata }\end{array}$ & $\begin{array}{c}\text { O envolvimento da } \\
\text { família no } \\
\text { desenvolvimento } \\
\text { de competências } \\
\text { em crianças com } \\
\text { dificuldades na } \\
\text { leitura }\end{array}$ & 2018 & $\begin{array}{c}\text { Perceber se os pais } \\
\text { de crianças com } \\
\text { dificuldades na } \\
\text { leitura realizam } \\
\text { atividades } \\
\text { educacionais com } \\
\text { seus filhos para } \\
\text { desenvolver } \\
\text { competências } \\
\text { leitoras. }\end{array}$ & $\begin{array}{l}\text { Esta investigação teve a finalidade de aferir se os pais } \\
\text { de crianças com dificuldades na leitura, realizam } \\
\text { atividades educacionais com os seus filhos e as quais } \\
\text { visam o desenvolvimento de competências leitoras } \\
\text { nos mesmos. Finalizado o trabalho de investigação, } \\
\text { conclui-se que os pais se sentem apoiados pelos } \\
\text { professores, ainda que pudessem usufruir de maior } \\
\text { apoio. Por sua vez, os professores sublinham a } \\
\text { importância de todas as partes, em particular, a } \\
\text { família e a escola (pois as partes também podem } \\
\text { incluir o psicólogo, o médico, ou outra figura } \\
\text { profissional) estarem envolvidas no processo e de } \\
\text { compreenderem a necessidade e a relevância do aluno } \\
\text { estar motivado para alcançar um resultado positivo. } \\
\text { Embora os pais se sintam apoiados, os professores } \\
\text { reconhecem a falta de preparação desta classe } \\
\text { profissional para intervir junto de alunos com } \\
\text { dislexia, seja ao nível do diagnóstico, seja ao nível da } \\
\text { intervenção. Contudo, reconhecem o seu papel neste } \\
\text { processo, defendendo uma atuação baseada num } \\
\text { plano elaborado em conjunto com a família e com os } \\
\text { profissionais, quando é o caso. Verificou-se que a } \\
\text { problemática da dislexia deveria ser abordada ao } \\
\text { longo do processo de formação inicial de professores, } \\
\text { até porque, o professor, para sugerir estratégias e } \\
\text { atividades, tem que conhecer esta perturbação e os } \\
\text { instrumentos que, por exemplo, permitem avaliar o } \\
\text { auociente de aprendizagem dos alunos, como também }\end{array}$ \\
\hline
\end{tabular}




\begin{tabular}{|l|l|l|l|l|}
\hline & & & $\begin{array}{c}\text { tem que ter conhecimento de estratégias e atividades } \\
\text { adequadas às dificuldades de cada aluno disléxico. } \\
\text { Ainda assim, os pais consideram que os professores } \\
\text { os informam devidamente das atividades que devem } \\
\text { realizar com os seus educandos, fornecendo-lhes } \\
\text { diversas sugestões. }\end{array}$ \\
\hline
\end{tabular}

FONTE: Elaborado pela autora. 


\section{$2^{\circ}$ string - Ensino Fundamental AND dislexia AND Metacognição}

\begin{tabular}{|c|c|c|c|c|c|}
\hline BASE & $\operatorname{AUTOR}(\mathbf{A})$ & TEMA & $\begin{array}{c}\text { DATA DE } \\
\text { PUBLICAÇÃO }\end{array}$ & $\begin{array}{l}\text { OBJETIVO DO } \\
\text { ESTUDO }\end{array}$ & CONCLUSÃO DO ESTUDO \\
\hline BVS & $\begin{array}{l}\text { Giovanna Beatriz } \\
\text { Kalva Medina; } \\
\quad \text { Fabíola } \\
\text { Fleischfresser de } \\
\text { Souza; Sandra } \\
\text { Regina Kirchner } \\
\text { Guimarães }\end{array}$ & $\begin{array}{l}\text { Funções } \\
\text { executivas e } \\
\text { leitura em } \\
\text { crianças } \\
\text { brasileiras com } \\
\text { dislexia do } \\
\text { desenvolvimento }\end{array}$ & 2018 & $\begin{array}{l}\text { Contribuir para o } \\
\text { desenvolvimento de } \\
\text { metodologias de } \\
\text { trabalho que se } \\
\text { concentrem na } \\
\text { remediação dos déficits } \\
\text { subjacentes ao processo } \\
\text { da leitura. }\end{array}$ & $\begin{array}{l}\text { Por último, destaca-se que a principal } \\
\text { implicação educacional deste estudo foi que, a } \\
\text { partir da constatação dos déficits apresentados } \\
\text { pelos participantes com dislexia, elaborou-se } \\
\text { um programa voltado ao desenvolvimento das } \\
\text { funções executivas que será aplicado na } \\
\text { segunda etapa deste estudo. }\end{array}$ \\
\hline Scielo & $\begin{array}{l}\text { Evelyn Budal } \\
\text { Porto Bovo; } \\
\text { Ricardo Franco } \\
\text { de Lima; } \\
\text { Fernanda } \\
\text { Caroline Pinto da } \\
\text { Silva; Sylvia } \\
\text { Maria Ciasca }\end{array}$ & $\begin{array}{l}\text { Relações entre as } \\
\text { funções } \\
\text { executivas, } \\
\text { fluência e } \\
\text { compreensão } \\
\text { leitora em } \\
\text { escolares com } \\
\text { dificuldades de } \\
\text { aprendizagem }\end{array}$ & 2016 & $\begin{array}{l}\text { Investigar as relações } \\
\text { entre as funções } \\
\text { executivas (FEs) e o } \\
\text { desempenho em fluência } \\
\text { e compreensão de leitura } \\
\text { de escolares com } \\
\text { dificuldades de } \\
\text { aprendizagem. }\end{array}$ & $\begin{array}{c}\text { O estudo demonstrou que há relações } \\
\text { significativas entre os componentes das FEs, } \\
\text { fluência e compreensão leitora. As maiores } \\
\text { correlações ocorreram com controle inibitório, } \\
\text { memória operacional e fluência verbal. É } \\
\text { possível inferir que as FEs possam contribuir } \\
\text { com os aspectos estratégicos e metacognitivos } \\
\text { da leitura, sendo que estudos posteriores podem } \\
\text { investigar as relações causais entre esses } \\
\text { construtos. }\end{array}$ \\
\hline BVS & $\begin{array}{l}\text { Francislaine } \\
\text { Flâmia Inácio }\end{array}$ & $\begin{array}{l}\text { Memória, estilos } \\
\text { intelectuais e } \\
\text { estratégias de } \\
\text { aprendizagem }\end{array}$ & 2016 & $\begin{array}{l}\text { Avaliar o desempenho } \\
\text { em memória, os estilos } \\
\text { intelectuais e as } \\
\text { estratégias de } \\
\text { aprensizagem nos alunos } \\
\text { do Ensino Fundamental }\end{array}$ & $\begin{array}{l}\text { Os assuntos trabalhados nesta pesquisa são } \\
\text { pouco abordados na realidade do professor e, } \\
\text { alguns deles nem mesmo são mencionados. } \\
\text { Levar tais temas para as escolas é de suma } \\
\text { importância no processo de aprendizagem, pois } \\
\text { abarcam desde o processamento da informação, }\end{array}$ \\
\hline
\end{tabular}




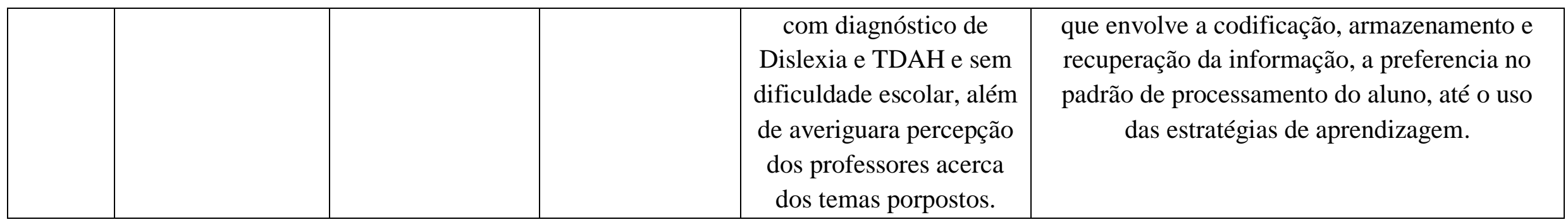

Fonte: Elaborado pela autora. 
Diante das conclusões expostas no quadro acima, foi gerada a nuvem de palavras de acordo com constância de palavras que apareceu em seus textos (Figura 1), através da Plataforma online WordArt. O WordArt é um criador de arte em nuvem de palavras on-line, esta ferramenta agrupa e organiza graficamente as palavras-chave evidenciando as mais frequentes.

Figura 1 - Nuvem de palavras
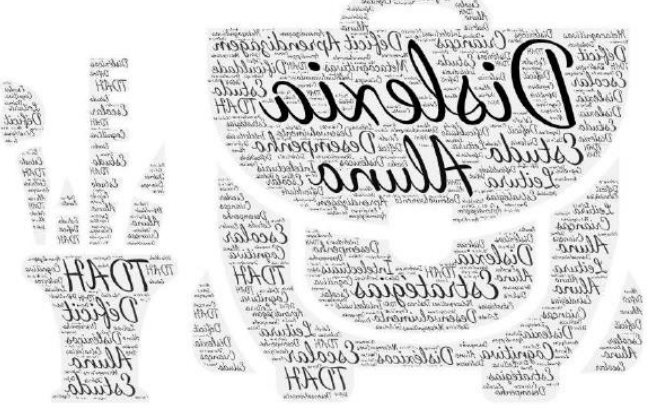

Fonte: Elaborado pela autora

Mediante a Figura 1, foi possível constatar que as palavras em evidência na nuvem pertencem as categorias desenvolvidas a partir da análise de conteúdo de Bardin. Todas as categorias advêm da sua frequência (Tabela 2), que diz respeito ao seu quadro referencial.

De acordo com o objetivo deste estudo, preferiu-se por caracterizar as palavras que apresentaram maior frequência no escopo do texto e, a partir dos seus conteúdos semânticos, tinham uma magnitude expressiva no contexto das concepções alinhadas a temática da gameterapia como tecnologia assistiva, como destacado na Figura 1. Tabela 2 Frequência das palavras presentes nos artigos publicados pelos internautas nas plataformas de bases científicas (BVS, WYLEI, SCIENCEDIRECT, PERIÓDICO DA CAPES, SCIELO).

TABELA 2

FREQUÊNCIA DAS PALAVRAS EXTRAÍDAS DAS CONCLUSÕES DOS ARTIGOS BAIXADOS DAS BASES CIENTÍFICAS.

\begin{tabular}{c|c|c} 
PALA VRAS & FREQUENCI & CA TEGORJA \\
\hline Dislexia & 13 & Família, Leitura e \\
Eluno & 13 & \\
\hline Estratégias & 12 & \\
\hline TDAH & 11 & Ensino Fundamental \\
\cline { 1 - 2 } Desempenho & 9 & $\begin{array}{c}\text { Dislexia e } \\
\text { metacognição. }\end{array}$ \\
\hline Aprendizagem & 9 & \\
\hline Escola & 8 & \\
\hline Cognitivo & 8 & \\
\hline Leitura & 7 & \\
\hline Dificuldade & 7 &
\end{tabular}

Fonte: Elaborado pela autora. 


\section{DISCUSSÃO}

A leitura é um processo por meio do qual se extrai e se capta informações de textos (por exemplo, páginas impressas, imagens, diagramas, legendas, gráficos, ilustrações, etc). Não se trata de mera ou simples decodificação de símbolos escritos em sons, nem tampouco de uma recepção passiva de uma imagem colhida em qualquer lugar no cérebro a partir da palavra escrita, com a qual pode ser associada. A leitura é um processo ativo, autodirigido pelo leitor em múltiplas formas e apresentando várias finalidades (FONSECA, 2009).

Seguem abaixo, as categorias temáticas elaboradas a partir da revisão sistemática integrativa:

\section{O QUE É A LEITURA?}

Ao pesquisar a definição e a etimologia da palavra leitura foi possível descobrir que o significado de leitura é algo bastante interessante, já que a palavra leitura deriva da palavra ler. Que em latim é descrito legere e tem como sua primeira definição "descrever, colher, escolher".

Segundo o site Origem da Palavra o sentido da palavra leitura legere quer dizer colher, escolher, recolher. Que tinha esses significados pois o objetivo de ler era o de escolher e definir corretamente as letras para a formação de uma palavra.

Porém a leitura é muito mais que apenas escolher e definir letras para a definição de uma palavra.

A leitura é um processo no qual o leitor realiza o trabalho ativo de construção de significado do texto, a partir dos seus objetivos, do seu conhecimento sobre o assunto, sobre o autor, de tudo que se sabe sobre a língua: características do gênero, do portador, do sistema da escrita... (Parâmetros Curriculares Nacionais - PCN, 2001, p. 53)

Porém definir o que é esse ato não é algo tão simples assim, pois segundo Leffa (1996, p. 09) isso depende de alguns fatores como: "linguístico, psicológico, social, entre outro fenômeno". Exemplo disso é que para ler se faz necessário a utilização de alguns sentidos, como a visão. Na verdade, o ato da leitura é "olhar para uma coisa e ver outra".

É importante lembrar que apesar da leitura usar primordialmente a visão, há também situações em que é possível fazer uma leitura através de sinais não linguísticos. Como a percepção dos sentimentos de alguém, por imagens em cavernas de civilizações antigas, ao observar um bairro e sua estrutura.

Ao analisar a definição do que é essa prática alguns autores a definem da seguinte forma:

"A leitura é uma ação de compreender e assimilar o pensamento ou as ideias do autor do texto". (LITTON, 1975)

"A leitura talvez é o melhor meio de impedir o perigoso raciocínio 'preto e branco' (o bem contra o mal) e de contrabalancear os instrumentos de persuasão e manipulação subconscientes". (BAMBERGER, 1991, p. 99)

"A leitura e a escrita são fundamentais para o aprendizado de todas as matérias escolares". (BRASIL, 2006)

Independentemente do tempo em que se fale da leitura ela sempre será descrita e interpretada como uma ação em que torne o homem mais capaz. Mais capaz de interpretar ideias, mais capaz de observar o mundo de uma forma diferente e sempre será capaz de tornar o homem um ser mais 
sábio, pois a leitura permite que o homem aprenda algo.

Mas o aprender algo como se dar essa etapa? Como a leitura e tudo que gira entorno dela está ligada? Estaria a leitura ligada ao processo de aprendizagem?

Compreender o processo da aprendizagem é algo bastante peculiar para compreender o fenômeno da leitura. Pois na leitura não basta apenas juntar letras e significados, se faz necessário entender o que se foi lido.

\section{NO ÂMBITO DA APRENDIZAGEM}

Quando falamos em aprendizagem, pensamos logo na capacidade que o ser humano tem de armazenar informações das mais variadas espécies para posteriormente aplicar em suas necessidades diárias. (BAPTISTA, 1999)

Acreditamos que todo indivíduo é capaz de aprender, não tudo que lhe for ensinado, mas aquilo que tem significado para a sua vida.

Aprender é ficar sabendo, é conhecer, para que se conheça é preciso de algo ou alguém que apresente ou mostre o objeto a ser conhecido. Nesse sentido a aprendizagem parte da relação sujeito/mediador/objeto. Sujeito, indivíduo que deseja conhecer. Mediador, pessoa ou instrumento que vai levar o sujeito ao objeto, que por sua vez é o que se pretende conhecer. E para que esta relação seja saudável é necessário que todos estejam na busca dos mesmos objetivos, dentro de uma relação igualitária. (BAPTISTA, 1999)

Segundo Vasconcelos (2011) para que a aprendizagem aconteça, não é necessário estabelecer hora e local específico, pois a partir do momento que nascemos já nos encontramos em fase de adquirir novos conhecimentos, uma vez que precisamos compreender o meio para que possamos viver bem e cada vez melhor. Existem determinadas coisas que somos capazes de aprender sozinhos, através dos nossos sentidos em decorrência dos nossos desejos, porém existem outras que para compreendê-las é preciso do auxílio de outro ser que já conhece, pois queremos aprender, mas não sabemos como. Existem ainda aquelas que precisamos aprender, mas pela falta de estímulos e pela pouca necessidade de uso deixamos de lado.

A aprendizagem ocorre nos mais variados momentos, locais e das mais variadas formas e razões. Podemos aprender durante um passeio, uma brincadeira, na igreja, no clube, numa viagem, no bairro onde moramos, na nossa própria casa. Este tipo de conhecimento que ocorre de forma aleatória que não exige organização prévia, não exige uma preparação específica é denominado por conhecimento assistemático, não depende de uma instituição apropriada. (BAPTISTA, 1999)

Zagury (2012) enfatiza que existe outro tipo de aprendizagem que para ser adquirida é necessária uma organização prévia das pessoas envolvidas no processo, é o conhecimento sistemático, uma vez que em toda sua essência é preciso uma sistematização, uma escolha do que vai ser aprendido, de quem vai mediar essa aprendizagem e uma separação, das pessoas que vão conhecer. Essa aprendizagem ocorre dentro de uma instituição que é a escola. Nela para que a aprendizagem aconteça ocorre anteriormente toda uma organização: divisão de setores, seleção do processo envolvido, separação das pessoas que querem aprender de acordo com sua faixa etária ou nível de aprendizagem, escolha do que vai ser ensinado e a forma como vai acontecer esse ensinamento. 
$\mathrm{Na}$ instituição escolar ocorre o que conhecemos por processo de ensino aprendizagem propriamente dito, que obedece a determinadas regras, estabelecidas por seus dirigentes, seguindo padrões da sociedade de acordo com uma hierarquia preestabelecida. $\mathrm{O}$ processo de ensino aprendizagem que acontece dentro da escola também é proveniente da relação sujeito/mediador/objeto. Nessa relação o sujeito ocupa o papel do educando, mediador é o professor junto com a equipe e o objeto é o conhecimento a ser adquirido. Esse conhecimento é previamente estabelecido através do planejamento educacional, elaborado pelo professor supervisionado pela equipe técnica e direção (ZAGURY 2012). A escola deve estar preocupada com o educando desde o seu ingresso ainda na fase da Educação Infantil, pois é a partir daí que a criança começa a adquirir interesses pelos conteúdos escolares, caso estes não sejam de seu interesse ela vai começar a ficar alheia durante o trabalho que o envolve. Mutschele (2010) afirmou em seu livro que a instituição escolar deve estar consciente das fases de desenvolvimento de seus alunos no intuito de escolher os conteúdos que se tornem adequados a cada uma dessas fases fazendo-se necessário também conhecer a clientela que vai ser trabalhada, estar consciente de seus interesses visando garantir uma aprendizagem significativa, onde deve ser analisado o processo de desenvolvimento do conhecimento de cada aluno. Esse processo segundo Piaget é sempre um processo de construção.

$$
\text { O resultado dessa construção }
$$

delimita em cada patamar, a capacidade do sujeito para aprender. Essa capacidade está circunscrita pelo que ocorre num dado patamar e intervém diretamente sobre o processo de desenvolvimento possibilitando a passagem para um novo patamar. Se essa aprendizagem se intensifica, a construção de um novo patamar poderá ocorrer mais rapidamente, dentro de certos limites.

A escola deve ter em mente os objetivos que pretende alcançar e que aluno ela pretende formar visando chegar a culminância desses objetivos. Para que isso aconteça a escola deve estabelecer uma Proposta Pedagógica coerente com seus objetivos. E esses objetivos devem partir principalmente na busca da formação de seus direitos procurando formar uma sociedade mais justa, mais humana. (MASETTO, 2011, p 44)

Para tanto é fundamental que alunos, supervisores, orientadores, diretor, funcionários, pais de alunos e principalmente os professores que, vão mediar os interesses, indicando pistas para que os seus educandos tenham um bom desempenho, estejam totalmente envolvidos com o processo ensinoaprendizagem. A escola por ser a instituição que se encarrega de sistematizar o conhecimento a ser transmitido aos educandos, deve conhecer as diferentes concepções a respeito do processo de ensinar e aprender, na tentativa de escolher a melhor concepção que se possa adequar a seus objetivos.

Segundo Masetto (2011, p 45), essas concepções se apresentam da seguinte forma:

\footnotetext{
- Abordagem Tradicional, enfatiza a transmissão de conceitos e a imitação dos modelos aprendidos. - Abordagem Comportamentalista, visa a obtenção de um determinado comportamento que deve ser mantido.

- Abordagem Humanista, a pessoa está incluída no processo de ensino-aprendizagem.
} 
- Abordagem Cognitiva, preocupação em como se dá a aprendizagem.

- Abordagem Sócio-Cultural, busca da superação da relação opressor-oprimido.

A escola enquanto instituição sistematizadora do conhecimento deve conduzir sua ação educativa baseando-se na concepção que busque valorizar o seu aluno de forma que possa construir seu conhecimento. As rápidas mudanças que estão ocorrendo na maioria das sociedades contemporâneas representam um grande desafio.

Sendo assim, mudam-se as relações sociais, as de trabalho, e a educação precisa ser repensada e transformada. Surge no mundo do trabalho um novo padrão que privilegia o trabalhador que desenvolve competências ligadas ao raciocínio, a capacidade de iniciativa, de cooperação e autonomia. Atualmente saber fazer é insuficiente. É necessário que o trabalhador se disponha a conhecer e principalmente, a saber aprender. (ZAGURY 2012).

Dentro dessa perspectiva a escola tem imensas tarefas a executar, uma vez que é ela que difunde conhecimentos e fornece instrumentos para compreensão do mundo, do outro e de si mesmo, além de desenvolver o sentido dos valores relacionados à solidariedade, à responsabilidade e à aceitação das diferenças culturais.

Freire (2013), afirmou que diante das mudanças no mundo do trabalho o papel da escola é de fundamental importância, pois o conhecimento é considerado como recurso controlador e fator de produção fundamental. Neste sentido o avanço da informática passou a exigir uma revisão no papel da educação, colocando para escola um desafio sem precedentes.
A escola hoje deve formar e capacitar os estudantes para aquisição de novas competências, em função de novos saberes que surgem e que exigem um novo tipo de profissional.

Segundo Freire, (2013): [...] o ato de educar exige do educador uma constante revisão de sua práxis, pois a natureza formadora da docência, que não poderia reduzir-se a puro processo técnico e mecânico de transferir conhecimentos, enfatiza a exigência ético-democrática do respeito ao pensamento, aos gostos, aos receios, aos desejos, à curiosidade dos educandos.

Diante dessas exigências a escola deve estar sempre em processo gradativo de ressignificação do conhecimento, sob o ponto de vista do ato de conhecer, que deve ser rico, cheio de contradições, oportunizando o surgimento da crise, lugar de conflito; por vezes o sujeito fica em completo desequilíbrio cognitivo frente ao seu saber.

É a hora da construção e reconstrução de hipóteses/ideias sobre o objeto. A partir daí, ocorrem os esquemas de ação mental como: assimilação, acomodação, adaptação e, finalmente, a equilibrar, tendo como resultado a aprendizagem. Estes esquemas de ação surgem tentativas para solucionar situações problemas que emergem no espaço escolar, bem como na vida cotidiana. (VEIGA,2014)

$\mathrm{O}$ instante da aprendizagem é extremamente sublime, prazeroso e, ao mesmo tempo, mágico. É quando o sujeito consegue fazer uma síntese do conhecimento, em virtude de ter se apropriado dele, incorporando-o de tal maneira a poder explicá-lo e generalizá-lo, aplicando-o em diversas situações e momentos da vida. 
Para que ocorra a aprendizagem, deve-se considerar as seguintes dimensões: a dimensão da inteligência, a dimensão do social, a dimensão do desejo e das outras linguagens. $\mathrm{O}$ professor participante desse processo deve trabalhar, objetivando fazer uma escola mais democrática, por isso humanizada, onde todos terão as mesmas oportunidades e consequentemente uma educação mais voltada para cidadania (VEIGA,2014).

A educação deveria ter o propósito de ajudar a despertar em cada pessoa a consciência de sua própria dignidade e sua capacidade de exercer a cidadania. A aprendizagem (educação) é instrumento que transforma a pessoa, tornando-a responsável pelo seu próprio desenvolvimento em benefício da humanidade.

A nossa educação se constrói nos espaços de convivência da vida. Uma boa ou má educação é o resultado do tipo de família, escola, Igreja, trabalho, sociedade e meios de comunicação que possuímos.

A família é nossa primeira escola, prepara a criança para a vida. Nela se cultivam modos de relacionar-se com os outros que duram toda vida. Uma boa educação na família poderia tornar $o$ indivíduo mais sensível, mais humano, sujeito consciente de sua responsabilidade e de seu papel no mundo como pessoa e como cidadão. (ROMÃO,2012)

A aprendizagem é um processo constante e a escola tem um papel especial nesse aprendizado e vai se tornar cada vez mais necessário porque ela é o espaço ideal para transmissão do saber. A educação não acaba nunca. Se alguém não está disposto a sempre aprender mais, acaba tornando-se defasado e obsoleto. Não se trata tanto de aprender coisas, mas de educar para saber viver em qualquer realidade.
Cada encontro entre pessoas acrescenta algo a nossa aprendizagem. Portanto o processo de ensino aprendizagem deve estar voltado para uma educação onde cada um possa conhecer e exercer a sua cidadania. Para tanto não basta saber é preciso que esse saber esteja em função de uma sociedade mais humana. No mundo de mudanças, trata-se de aprender e colocar o aprendizado a serviço de uma melhor qualidade de vida para todos. (VEIGA,2014).

$\mathrm{O}$ processo de ensino aprendizagem decorre dos mais variados fatores, por isso não podemos considerar a escola como o único ambiente onde acontece aprendizagem, abandonando assim a ideia de que a educação é uma prática que ocorre exclusivamente na escola, obedecendo a padrões rígidos de sistematização do saber. (OSÓRIO, 2012)

A instituição escolar não tem condições de trabalhar sozinha, ela necessita do apoio da família, da comunidade. Partindo do pressuposto de que a educação é considerada como um processo de crescimento individual $\mathrm{e}$ coletivo de descobertas, que acorre em casa, na escola, na rua, na igreja, enfim, em qualquer lugar.

O papel da escola é a complementação da educação iniciada nos lares, segundo Osório (2012, p.65):

[...] sua primeira e talvez mais fundamental tarefa é facilitar o processo de diferenciação e individualização da criança, oferecendo-lhe uma espécie de introdução à vida social fora do âmbito doméstico. Costuma-se dizer que a família educa e a escola ensina, ou seja, a família cabe oferecer à criança a pauta ética para a vida em sociedade e a escola instruí-los, para que possam fazer frente as exigências competitivas 
do mundo na luta pela sobrevivência.

A família é e continuará sendo o porto seguro dos indivíduos. Por mais que entrem em atrito com os pais e familiares, é nesta mesma família onde se busca refúgio quando as situações no mundo, na sociedade lhes são adversas.

Seja qual for o tipo de estrutura familiar a que o ser humano pertença, ela é sua família, a sua segurança, o espaço onde o jovem, $o$ adolescente pode ser ele mesmo, sem medos e sem máscaras. A família, sendo o ambiente que a criança está mais presente, deve contribuir de maneira bastante significativa, pois a criança necessita de um referencial que preencha suas necessidades afetivas para adquirir uma aprendizagem significativa (PERRENOUD,2015).

Quando a família não se faz presente na vida da criança, percebe-se muitas vezes a falta de estímulos, por parte da criança, para aprender, tornando-se agressiva, desatenta, omissa nas atividades, gerando problemas que acarretam a não aprendizagem.

Uma questão de fundamental importância refletida em nossas escolas devido à "ausência" da família é a indisciplina e está por sua vez origina o fracasso escolar.

Vasconcelos (2011) em seu livro Disciplina - Construção da Disciplina Consciente e Interativa em Sala de Aula e na Escola, relaciona alguns itens que originam a indisciplina na escola.

O primeiro deles é a desagregação convivência qualitativamente insuficiente de diálogo, carga excessiva de trabalho.

As famílias devido a uma exigência do mundo atual e do avanço tecnológico não tem mais tempo para se reunir, pais e filhos estão sobrecarregados de trabalho, não existindo tempo para conversa. "A família não passa assim de uma reunião de desconhecidos íntimos”. (OSÓRIO, 2012)

Um outro item é a distância da escola, a falta de conhecimento da proposta da escola, transferência de responsabilidade, falta de participação. A maioria das famílias estabelece critérios para escolha da escola de seus filhos que estão completamente distantes da proposta pedagógica da escola, elas nem ao menos a conhecem, apenas transferem para a escola a função de educar seus filhos em todos os aspectos inclusive naqueles que pertencem à família, preocupando-se apenas com a aprovação de seus filhos, sem muito contribuir para a melhoria da qualidade da escola.

Superproteção dos pais em relação aos filhos, não lhes atribuindo responsabilidades nas classes mais abastadas, inserção da criança logo cedo no mundo do trabalho, nas classes populares, é outro item colocado por Vasconcelos que origina a indisciplina escolar (OSÓRIO, 2012).

As famílias tendem a oferecer demais aos seus filhos, dão tudo pronto a hora que eles querem, sem deixá-los perceber o valor das coisas. Em oposição a isso existem as famílias que por não terem condições financeiras colocam seus filhos ainda criança para trabalharem, os mesmos chegam à escola cansados sem condições de produzir o que poderiam.

A dificuldade dos pais em colocar limites entre o espontaneísmo e o autoritarismo é abordado por Vasconcelos (2012) como fator que produz a indisciplina na escola. Os pais interpretam a relação igualitária de debate, de se escutar a criança como forma de excluir qualquer tipo de autoridade, com receio de que impondo limites geram problemas como frustração e 
trauma, esquecendo-se de que "educar implica sempre maior ou menor grau a necessidade de limitar, de às vezes dizer não, de negar algumas coisas aos filhos" (ZAGURY, 2012).

Sabe-se que uma série de fatores interferem no processo educativo da criança como: o nível de renda familiar, o grau de instrução dos pais, a falta do afetivo. Por estes e outros fatores citados a família passa muitas vezes um sentimento de incapacidade frente a educação dos seus filhos.

As transformações contínuas que a família vem sofrendo, especialmente em função das demandas de modernização, originam diversas e possíveis configurações do núcleo familiar. Por isso não se pode considerar como ideal a família nuclear, formada de pai, mãe, filhos.

Hoje encontramos na sociedade várias estruturas familiares que oferecem aos filhos, carinho, amor, segurança, oportunizando uma ótima formação aos homens e mulheres de amanhã. É preciso que a sociedade, e em especial os educadores, parem de ver e pensar como problemáticos os filhos de famílias com estruturas diferenciadas, muitas dessas famílias cumprem e muito bem o seu papel e têm filhos muito bem formados. (ZAGURY, 2012).

A família nuclear preencheu bem as necessidades de uma época. A estrutura ideal de uma família é aquela que serve aos membros, oportunizando o crescimento, a felicidade, a verdadeira troca de amor e entrega ao mundo pessoas completas, íntegras, capazes de transformar uma sociedade. O que faz da família uma família é o nível de amor gratuito e espontâneo que impregna as relações dos membros entre si.

Embora alguns casais se separam, continuam sendo pai e mãe. $O$ que se dissolve juridicamente é a sociedade marido e mulher e nunca a missão de pai e mãe. Este erro tem custado muito caro aos nossos jovens. Se os pais ouvissem mais seus filhos, prestassem atenção em suas atitudes e os observassem com os olhos do coração, os filhos teriam mais facilidade de compreender e serem compreendidos pelos pais, em como amar e lidar com eles. (VIÉGAS, 2012)

A criança gosta de sua família e precisa encontrar nela, pais presentes e eficientes que proporcionem: segurança, amor, compreensão, participação, autonomia, limites, diálogo, objetivos claros de vida, vivência de valores, respeito. A família é o melhor lugar para que a criança ou o jovem se desenvolva, seja ele mesmo, um ser livre e de conquistas.

É na íntima e particular história vivida nos primeiros dias e meses de vidas que será impressa em nós uma marca profunda e indelével, que influenciará para sempre em todas as outras histórias que vamos viver vida afora.

Segundo Cerveny e Berthoud (2008, p.54):

[...] dependendo da orientação oferecida pelos pais até o momento dependendo do tipo de vínculo construído no relacionamento com os pais, a criança pode encontrar mais ou menos facilidade em sua adaptação ao novo grupo de instrução, o qual, por sua vez irá ocasionar mais ou menos estresse em seu sistema familiar. Crianças que experimentaram vínculos seguros, em que os limites são claros com os familiares, demonstram facilidade em assimilar as novas regras de funcionamento, brincam e produzem sem dificuldades. Por outro lado, crianças cujos pais apresentam dificuldades em trabalhar com limites, inseguros 
em dizer não e frustrar os filhos, apresentam muitas vezes dificuldades nas relações sociais com o sistema escolar e dessa forma, o sistema familiar também sentirá a pressão e o estresse que vínculos inseguros ocasionam.

Família e escola devem estabelecer uma relação amigável buscando sempre uma maior integração. Uma vez que a educação é uma tarefa complexa, delicada e sutil que exige conhecimento, dedicação e amor. Sobre isso Mutschele (2010) afirma,

[...] é necessário, pois que os pais abram a sua inteligência e o coração para função cada vez mais difícil de educar. E, sobretudo que não se esqueça de que educar dignamente os filhos é um dever sagrado e imperioso que não deve ser deixado de lado unicamente por conta da escola. Por isso faz-se mister que a família reaja contra os fatores dissolventes da vida moderna e se conserve unida e harmônica numa atmosfera de afeição de solidariedade e compreensão. Isto não significa, porém opor-se a escola instrumento de ação educativa da família.

A família e a escola, longe de se oporem auxiliam-se, completam-se devem manter um íntimo convívio e uma estreita colaboração. A eficiência, a elevação e a dignidade da educação das novas gerações muito dependem da harmonia, da união, identificação entre família e escola.

Através dessa parceria entre escola e família é possível identificar, trabalhar e tratar problemas detectados com relação a aprendizagem do aluno e compreender o que eles são.

\section{Distúrbios de Aprendizagem}

Os distúrbios da aprendizagem envolvendo a leitura oral e a escrita, podem apresentar diversas causas. Portanto, é indispensável que se analise a leitura oral e silenciosa antes de avaliar a escrita, visto serem as dificuldades de escrita, na maioria das vezes, decorrentes de uma leitura lenta, analítica, impregnadas de trocas de sílabas ou palavras, sem pontuação, nem ritmo e incompreensível. (ASSUNÇÃO E COELHO, 2012)

Com base em diversas pesquisas realizadas pelo Ministério da Educação e Cultura, podem-se apontar várias causas como responsáveis pelas dificuldades escolares e pelos altos índices de evasão e reprovação escolar, tais como: ausência de estimulação nas habilidades básicas necessárias a alfabetização; métodos de ensino inadequado; problemas emocionais; dislexias e falta de maturidade para iniciar o processo de alfabetização.

Segundo Assunção e Coelho (2012), uma das dificuldades que merece atenção é a maturação da criança: A maturação não é nada mais nada menos do que $\mathrm{O}$ desenvolvimento das estruturas corporais, neurológicas e orgânicas das pessoas e que abrange padrões de comportamentos resultantes da atuação de algum mecanismo interno. (ASSUNÇÃO E COELHOQ, 2012).

É importante, que exista uma preocupação em determinar precocemente a causa da dificuldade para aprender. $\mathrm{O}$ diagnóstico precoce do distúrbio de aprendizagem é um ponto fundamental para a superação das dificuldades escolares.

Deve ficar claro, que a aprendizagem da leitura e da escrita é um processo complexo que envolve vários sistemas e habilidades é, não se pode 
esperar, portanto que seja determinado um único fator, como o responsável pela dificuldade para aprender. $\mathrm{Na}$ verdade, os distúrbios de aprendizagem, dependem de causas múltiplas, cabendo ao profissional evidenciar a área mais comprometida.

Capovilla (2010) lista algumas dislexias comumente encontradas no dia-adia educacional.

- Dislexia visual: há distúrbios no sistema de análise visual das palavras. Os erros de leitura mostram uma semelhança visual entre a escrita da palavra pronunciada e da palavra alvo.

- Dislexia de negligência: os distúrbios também estão no sistema de análise visual, ocorrendo erros principalmente na parte inicial da palavra. Leitura letra - a - letra: há distúrbios no reconhecimento global de palavras, ou seja, no processamento paralelo das letras.

- Dislexia atencional: há dificuldades na codificação das posições específicas das letras nas palavras.

- Dislexia fonológica: há dificuldades na leitura pela rota fonológica e, portanto, a rota lexical é preferencialmente usada.

- Dislexia profunda: há sérios distúrbios no processo de conversão grafema - fonema e algum distúrbio na rota lexical.

- Dislexia superficial: há sérios distúrbios na rota lexical e distúrbios na rota fonológica. Porem, atualmente há uma tendência em não diferenciar a dislexia superficial da dislexia morfêmica.

$\begin{array}{ccr}\text { O } & \text { reconhecimento } & \text { das } \\ \text { características } & \text { precocemente, }\end{array}$ consequências, as soluções e as adaptações pertencem a educação. Não existem disléxicos entre analfabetos, porque a dislexia é uma dificuldade duradoura da aprendizagem da leitura e aquisição do seu mecanismo.

A maturação é considerada o ponto fundamental para a aquisição da leitura. A leitura imatura não está preparada para essa nova etapa da alfabetização e isso vem acarretar um problema futuro no que diz respeito à dificuldade de aprendizagem na leitura. Condemarin (2009) nos diz que: "a imaturidade na iniciação da aprendizagem constitui uma causa frequente de dificuldade na aprendizagem da leitura".

Uma das principais características do disléxico é a sua leitura silenciosa. Condemarin (2009), afirma que "aparentemente ele efetua a leitura silenciosa, mas pelo que se observa, ele mexe com os lábios e naqueles mais nervosos, há um murmúrio perceptível”. Isso é resultante da deficiência na soletração, pois é preciso revisualizar auditivamente as letras. E como uma leitura silabada sem respeitar a pontuação, tornando a leitura incompreensível.

Geralmente, quem tem dificuldade na leitura, carrega esse problema pela vida toda, mas há casos em que a reeducação consegue amenizar o distúrbio, isso não quer dizer que o portador consiga lê sem nenhuma dificuldade, ele vai apenas tentar superá-la por outros meios.

Goodglass (2009) afirma que se pode conceber que a linguagem está subordinada a uma ação mutua entre capacidade sensorial - motora, associações simbólicas e as variações sintáticas usuais. Tudo isso em dependência da aptidão intelectual de quem se expressa, com o intuito de obter a comunicação almejada.

Várias são as teorias que procuram explicar o desenvolvimento da dislexia. Critchley (2012, p.35), estudou sob o enfoque neurológico e indicou que o termo dislexia e outros são derivados de analogias 
com os estados afásicos, especialmente dos adultos.

Afasia, entidade complexa, na qual a criança apresenta severas dificuldades na aquisição da audição, da fala e igualmente da leitura e da escrita. Para o diagnóstico diferencial, Critchley (2012, p.35), considera indispensável a presença de: persistência na idade adulta, erros específicos na leitura e na escrita, incidência na família e frequente associação a outros déficits simbólicos.

Dislexia é uma alteração nos neurotransmissores cerebrais que impedem uma criança de ler e compreender com a mesma facilidade com que o fazem as crianças da mesma faixa etária, independente de qualquer causa intelectual, cultural ou emocional. Todo o desenvolvimento da criança é normal, até entrar na escola. E um problema de base cognitiva que afeta as habilidades linguísticas associadas a leitura e à criança (CONDEMARIN, 2009).

Há vários autores que definem a dislexia como um termo empregado em um sentido mais amplo.

Porém, boa parte dos estudiosos no assunto, concordam com Condemarin (2009), quando ele afirma que: O termo dislexia é aplicável a uma situação na qual a criança é incapaz de ler com a mesma facilidade com a qual leem seus iguais; apesar de possuir uma inteligência normal, saúde e órgãos sensoriais intactos, liberdade, emocional, motivação e incentivos normais, bem como instrução adequada.

Os principais padrões de disfunção na leitura, podem ser divididas em dislexias periféricas e centrais.

Nas dislexias periférica, os distúrbios ocorrem na análise visual, ou no reconhecimento das palavras. Já nas dislexias centrais, os distúrbios ocorrem em componentes das rotas fonológicas.

Ao compreender que a criança que tem dislexia tem uma grande dificuldade na hora de assimilar, compreender, memorizar, raciocinar e interpretar conteúdos relacionados as leituras e a escrita. Fazendo com que o mesmo tenha uma grande incapacidade em sua metacognição que nada mais é que a compreensão do aprendizado.

A melhor forma de trabalhar essa disfunção é a junção da escola com a família. Pois o aluno disléxico terá mais problemas em atividades que precise desenvolver mais percepções, reações e competências.

De uma forma mais ampla a Cognição é processar informações com a finalidade de perceber, integrar, compreender e responder adequadamente aos estímulos do ambiente, levando o indivíduo a pensar e avaliar como cumprir uma tarefa ou uma atividade social.

Ao considerar a escola e a família como elementos básicos para a formação e orientação de leitores, não se pretende de forma alguma tecer uma apologia sobre essas duas instituições sociais e sobre as funções que elas devem desempenhar no desenvolvimento da leitura em nosso contexto.

De acordo com Silva (2008), "um discurso louvando a família e glorificando a escola brasileira atual, poderia gerar a imagem de um idealismo exacerbado ou de um teorismo oco que não leva em conta os fatos sociais concretos".

Longe disso, a preocupação é voltada a tentativa de estabelecer a relação entre família, escola e sociedade, verificar as consequências dessa relação para o surgimento de homens leitores e a luz da experiência e percepção da realidade 
presente, chamar a atenção para alguns aspectos históricos e progressivamente congelados, mas provavelmente existindo em potencial, dentro de nossa estrutura familiar e educacional.

Segundo Silva (2008) recuperar e repetir, reconsiderar e fazer, resplandecer esses aspectos, de modo que pais e educadores brasileiros possam revê-los à luz da consciência crítica, é ao mesmo tempo tentar construir uma utopia, uma proposta possível de ser concretizada, quando esses mesmos pais e educadores, decidirem pela transformação das circunstâncias sociais alienantes.

O ensino escolar é uma prática social decidida e estabelecida pela sociedade moderna a fim de formal e institucionalmente, transmitir a cultura às novas gerações. Tomando como parâmetro essa função da educação escolar, afirma-se que seria difícil conceber uma escola onde o ato de ler não estivesse presente. Tomando como base certos conhecimentos sobre o sistema educacional brasileiro e o de outros países, não se correria o risco em afirmar que o processo de transmissão e aquisição da cultura, como regulamento executado no período de escolarização formal dos indivíduos, sempre envolve a mediação do material escrito.

Por isso mesmo, o ensino das séries iniciais pode ser tomado como sinônimo de ensino da leitura, de modo que as crianças possam se situar no mundo da escrita, elemento este que melhor caracterizar uma sociedade letrada. A partir daí, a escola vai estimulando as habilidades de leitura dos alunos-leitores e proporcionando situações nas quais eles possam ler para aprender.

O que facilita não apenas na postura do aluno leitor, mas o seu convívio como ser da sociedade mostrando assim a esta que há uma possibilidade deste leitor, juntamente com a escola trabalhar e conviver tranquilamente em sociedade e ter uma identidade.

A identidade é construída principalmente nas relações dos sujeitos com dois grupos básicos, que são as instituições sociais mais importantes durante os anos de formação da criança, o grupo familiar, cujo objetivo são as relações de afeto e o grupo escolar, cujo objetivo são as relações de aprendizagem de natureza complexa (GROSSI, 2013 p.134).

Em cada experiência grupal, o sujeito enriquece a sua individualidade, acrescenta a sua identidade e cresce como sujeito social.

$\mathrm{O}$ ato de aprender sempre pressupõe uma relação com outra pessoa, a que ensina. Esta relação vem carregada de fortes componentes afetivos. $\mathrm{Na}$ prática, as relações vividas entre quem ensina e quem aprende são pautadas por regras e muitos sentimentos.

Por isso, convém observar que atitudes críticas dos pais e, mais tarde, dos professores, para com as fantasias, as produções, respostas e ideias da criança em desenvolvimento, são introjetadas por ela, fazendo com que iniba sua capacidade de pensar e de criar.

É preciso compreender que a família tem um papel fundamental na aprendizagem do aluno. É ela em muitos momentos que pode e vai influenciar a atitude e postura dentro da escola, é a interação entre a escola e a familiar que influencia na postura de um ser leitor e por fim no na aprendizagem deste.

A família constitui instituição relevante no processo de reprodução social, que inclui a reprodução biológica e a tarefa de socialização, mediante a qual normas, valores e representações que organizam e 
dão sentido à vida social são transmitidos aos filhos.

Para realizar esse processo de reprodução, a família configura-se como grupo de convivência organizado por elementos culturais, no qual os interesses individuais de cada um de seus integrantes se conjugam com o interesse coletivo da unidade doméstica como um todo (ROMANELLI, 2010).

Enquanto grupo de convivência, a família organiza o consumo de bens materiais graças à cooperação econômica de seus componentes, que ocorre mediante a contribuição de ingressos monetários e também por meio da produção de valores de uso. A produção desses valores inclui tarefas domésticas, em geral realizadas por mulheres, as quais abrangem atividades como preparo de alimento, cuidados com as crianças, com a moradia e com a indumentária etc. (DURHAM, 2003).

Mas a família é grupo onde também se consomem bens simbólicos, isto é, representações diversas, pois é na unidade doméstica que "se concentram informações sobre a sociedade e onde se elabora a interpretação dessas informações" (DURHAM, 2003, p.210).

Por isso, a vida doméstica não é meramente instância de reposição do instituído, mas configura-se como espaço de reelaboração das representações sobre a esfera pública, e envolve o modo como os indivíduos interpretam, dentre outros, o universo do trabalho, da política, do sistema educacional, da religião, do lazer.

A convivência entre os integrantes da família é um processo de recriação tanto de representações quanto de formas de relacionamento e de busca de novas estratégias de sobrevivência para enfrentar dificuldades como ocorre com famílias de classes populares.
Essas classes podem ser consideradas como constituídas pela população pobre dos centros urbanos, que vive em condições financeiras precárias, decorrentes da reduzida qualificação ocupacional e da baixa escolaridade de seus integrantes, que têm acesso limitado aos serviços públicos, como educação e saúde. (ROMANELLI, 2013)

A importância do rendimento do trabalho dos filhos para assegurar $\mathrm{o}$ consumo de bens e serviços necessários à sobrevivência e reprodução do grupo doméstico foi documentada em estudos sobre as classes populares (MACHADO, 2014).

Esses estudos também apontam a importância que as famílias das classes populares atribuem à escolarização dos filhos, a qual resulta da representação que pais e filhos fazem da escola e do mercado de trabalho.

Isto é, a possibilidade de se conseguir emprego e melhores colocações no interior das empresas está associada, nas representações da família, ao acesso ao ensino público - fundamental e médio - o que é considerado pelos integrantes da unidade doméstica como um direito social que o Estado tem obrigação de garantir a todo cidadão.

É nesse quadro de experiências vividas pelas famílias de classes populares que se pode situar a relação dos adolescentes - enquanto estudantes e trabalhadores, isto é, co-provedores do consumo doméstico - com o sistema de ensino e com o mercado de trabalho.

A adolescência não é vivida de um único modo em todas as sociedades. Embora não haja uniformidade quanto aos limites etários que delimitam a adolescência, ela é situada entre 12 e 18 anos, de acordo com o Estatuto da Criança 
edo Adolescente - ECA, e entre 10 e 19 anos, como sugere a OMS - Organização Mundial de Saúde - (2009).

A oscilação nesses limites deve-se ao fato de que o critério etário não pode ser tomado isoladamente para caracterizar essa fase, já que:

Nós sabemos hoje que as idades da vida, embora ancoradas no desenvolvimento biopsíquico dos indivíduos, não são fenômeno puramente natural, mas social e histórico, datado, portanto, e inseparável do lento processo de constituição da modernidade, do ponto de vista do que ela implicou em termos de ação voluntária sobre os costumes e os comportamentos (PERALVA, 2010, p. 15).

Deixando de lado o critério exclusivo da idade, pode-se considerar essa fase a partir da emergência de novas formas de sociabilidade dos adolescentes com diferentes esferas da vida social, quando passam a viver sentimentos conflitantes e procuram autonomia e independência diante dos pais e dos adultos e amparo no grupo de pares.

Nesse processo, caracterizado como um período de revisão, autocrítica e transformação, de vital importância para o desenvolvimento da personalidade (Coleman, 2012), o adolescente, lentamente, constrói sua identidade e, de simples espectador, assume postura mais questionadora e ativa em relação aos diferentes contextos sociais de que participa.

Nas sociedades capitalistas ocidentais a adolescência constitui uma fase de transição conturbada, que tende a prolongar-se, inclusive nos países economicamente mais desenvolvidos
No Brasil, onde a desigualdade social convive com a diversidade cultural, a adolescência apresenta características específicas, que variam de acordo com a camada ou classe social, com o gênero, com o período histórico e com a cultura em que o adolescente está inserido (ALVESMAZZOTTI, 2012).

\section{CONSIDERAÇÕES FINAIS}

A família a o trabalhar a leitura com o aluno permite que esta possa compreender o comportamento metacognitivo que caracteriza a compreensão de como o ato de ler acontece. Passa-se a entender que o leitor, não somente sobre o conteúdo do texto, mas sobre o próprio processo de compreensão.

O objetivo deste trabalho era integrar a produção científica sobre o hábito da leitura no ambiente familiar, mas este foi muito mais além que isso. Com o desenvolvimento deste é possível compreender com essa instituição pode ser de grande valor ao acompanhar o ato da leitura, ajudando a criança a superar barreiras e dificuldades que esta possa a vir passar na escola com a falta ou com a incapacidade de ler e compreender um assunto.

Assim, com o desenvolvimento deste mediante as fontes bibliográficas é possível compreender que ler não é apenas assimilar conteúdos, mas ler com a família é desvendar problemas e melhor as condições de vida de uma criança e até mesmo de sua família.

Espera-se que este estudo possa ser mais um veículo que some conhecimento científico e que este sirva de interesse para futuras pesquisas relacionadas a família, a leitura e o processo de aprendizagem. 


\section{REFERÊNCIAS}

Alves-Mazzotti, A. J. (2012). Repensando algumas questões sobre o trabalho infantojuvenil. Revista Brasileira de Educação. 19, 87-98.

ASSUNÇÃO, E. E COELHO, J.M.T. Problemas de Aprendizagem. $3^{\mathrm{a}}$. Edição, São Paulo, Ática, 2012.

BAMBERGER, Richard. Como incentivar o hábito da leitura. $5^{\circ} \mathrm{Ed}$. São Paulo: ática, 1991, p. 07-106.

BAPTISTA, J. (1999). O Sucesso de Todos na Escola Inclusiva. In: Uma Educação Inclusiva a partir da escola que temos. Conselho Nacional do Ministério da Educação.

BRASIL, Parâmetros Curriculares Nacionais (PCN): Introdução. Brasília: Sec. De Educação Fundamental- Brasília: MEC/SEF, 1997.

Indicadores da qualidade na educação: dimensão ensino e aprendizagem da leitura e da escrita /Ação Educativa. São Paulo: Ação Educativa, 2006

CAPOVILLA, A. G. S. E CAPOVILLA, F.C. Problemas de Leitura e escrita: como identificar, prevenir e remediar numa abordagem fônica. Memnon edições científicas, 2013.

CERVENY, C. e BERTHOUD, B.

Família e Ciclo Vital. São Paulo: Casa do Psicólogo, 2008.

CRITCHLEY, Simon. The Faith of the faithless - Experiments in political theology. New York, Versos, 2012.
CONDERMARIN, M. E CHADWICCK, Marina. A escrita crítica e formal. Porto Alegre: Artes Médicas, 2009.

DURHAM, E. R... Desigualdade educacional e cotas para negros nas universidades. Novos Estudos. CEBRAP, S. Paulo, v. 66, p. 3-22, 2003.

GOODGLASS, Harold. Source, Braind and language, Volume 83. Publisher: Academia Press, 2009.

GROSSI, Esther Pillar; BORDIM, Jussara (Organizadoras). Paixão de aprender. $2^{\text {a }}$ ed. Petrópolis: Vozes, 2013.

FREIRE, Paulo. Política e educação. São Paulo: Cortez, 2013.

LEFFA, Vilson J. Aspecto da Leitura. Porto Alegre: Sagra: DC Luzzato, $1^{\circ}$ edição, 1996.

A leitura da outra língua.

Leitura; Teoria e Prática, Campinas, Associação de Leitura do Brasil, v. 8, n. 13, p. 15-24, 1989.

LITTON, Gaston. Os leitores e seus livros. Ed. Brasileira, rev. Adap. São Paulo: McGraw-Hill do Brasil, 1975. p. 435. (série de biblioteconomia)

MACHADO, Ana Maria. O hábito da leitura. São Paulo: abril. NOVA ESCOLA. Revista do Professor, setembro de 2014.

MASETTO, Marcos. Didática: A aula como centro. $4^{a}$ ed. São Paulo, FTD (Coleção Aprender a Ensinar). 2011.

MUTSCHELE, Mary Santos. Problemas de aprendizagem da criança. $3^{a}$ ed. São Paulo: Edições Loyola, 2010. 
Organização Mundial da Saúde. World Health Statistics 2009. Geneva: WHO; 2010. Disponível em:

<http://www.who.int/whosis/whostat/EN_ WHS10_Full.pdf $>$ Acessado em 25 de agosto de 2019

ORIGEM DA PALVRA. Leitura.

Disponível em:<

https://origemdapalavra.com.br/palavras/le itura/>, acessado em 18 de agosto de2019.

OSÓRIO, L. C. Casais e famílias: uma visão contemporânea. Porto Alegre:

Artmed, 2012.

Parâmetros Curriculares Nacionais (PCN)

Língua Portuguesa- $1^{\mathrm{a}}$ a $4^{\mathrm{a}}$ séries.

Brasília. Sec. De Educação Fundamental, 2001, p. 53.

PRATA, C. S. O. O envolvimento da

família no desenvolvimento de competências em crianças com dificuldades na leitura, 2018.

PERALVA, A. T. (2010). O jovem como modelo cultura. Em: Juventude e Contemporaneidade. - Brasília: UNESCO, MEC, ANPEd. 284 p. (Coleção Educação para Todos; 16).

PERRENOUD, Philipe. Avaliação. Porto Alegre: Artes Médicas, 2015.

ROMANELLI, O.O. História da educação no Brasil (1930/1973). 38.ed. Petrópolis:

Vozes, 2010.

ROMÃO, José Eustáquio. Avaliação

Dialógica: Desafios e Perspectiva. São

Paulo: Cortez, 2012.

SILVA, C. L. C... A criança na

Linguagem: enunciação e aquisição;

Pontes, 2008
UNESCO (1981). La jeunesse dans les annés 80. Paris: Les Presses de Unesco, 2010.

VASCONCELOS, Celso do S. Construção do conhecimento em sala de aula. Caderno Pedagógico do Libertad. São Paulo: Liberdade, 2011.

VEIGA, I. P. A. (Org.) Escola: espaço do projeto político-pedagógico. 4 . ed.

Campinas: Papirus, 2014

VIÉGAS, L. Progressão continuada e suas repercussões na escola pública paulista: Concepções de educadores. Dissertação de Mestrado, Universidade Estadual de São Paulo, São Paulo 2012.

ZAGURY, Tânia. Comunicação entre pais e filhos. A linguagem de sentir. São Paulo: Saraiva, 2012. 